\title{
EDITORIAL
}

\section{COVERAGE OF SCIENTIFIC RESEARCH BY THE NEWS MEDIA}

The New England Journal of Medicine published an article on coverage by the news media of the benefits and risks of medications by Moynihan et al(l). These authors studied 207 news media stories reporting on benefits and risks of pravastatin (a cholesterol lowering drug), alendronate (a biophosphonate for treatment and prevention of osteoporosis) and aspirin (when used for prevention of cardiovascular disease). They concluded that news media stories about medications may include inadequate or incomplete information about benefits, risks and costs of drugs as well as the financial ties between the study groups or experts and the pharmaceutical manufacturers. This article is, in many ways, an eye-opener, and prompted Robert Steinbrook, deputy editor of the New England Journal of Medicine to write an editorial on the theme(2).

Media coverage of scientific research has been of interest to me for quite some time. Together with journalists lay in health sciences and science writers working for various media companies, I have organized and participated in several training workshops dealing with the subject. During these workshops, we have noted the extreme stands taken by scientists on the one hand, and the media journalists on the other. However, the reasons behind these stands are understandable. Typically, the Kenyan media owners thrive on the volume of sale of their papers. This makes their journalists want to report sensational stories aimed at capturing wide readership. There is nothing fundamentally wrong with sensational stories, but the fact is that many of them tend to appear exaggerated, generalised and at times frankly biased. Such attributes of a report tend to discourage scientific researchers who, on the whole, have a tendency to be rather conservative, cautious, overly methodological, and bureaucratic. Furthermore, scientific language is rather dull and specific, thus lacking the flowery tint that attracts the public reader towards the newspaper stories. The scientific jargon which is popular with many researchers also discourages the lay reader. Clearly therefore, a compromise has to be found.

One may ask why it is important that research findings should be communicated in the lay print media, especially in the case of a developing country like Kenya. I consider that the resources used by the researcher are, in principle, provided by tax payer, the so-called common man (the mwananchi). Typically this is the person who lives in impoverished circumstances in the rural areas or in the poor urban slums. This person is a victim of infections and infectious diseases because of a multitude of reasons; one being lack of clean and safe water. This person is prone to being malnourished and his children will be underfed too. $\mathrm{He}$ is likely to be ignorant on many health issues and would suffer several illnesses because of such lack of proper health information. The researchers and other health professionals should consider it their professional and moral duty to inform and educate the rural poor and the urban slum dweller in order to empower them to take care of their own health.

If this thesis is accepted that the ordinary person should be informed of research findings, the subsequent questions are: how should it be done?, by who should it be done?, what details should be included?, and what precautions should be observed?

Several inferences can be drawn from the conclusion of the article published in the New England Journal of Medicine referred to above. The inferences include the fact that such news media stories could be misleading and create some degree of complacency or undue scare. And one is considering the situation in a highly developed country - the United States of America. The scenario is likely to be comparatively worse in the less developed countries .

I have often recommended that two precautions must be observed. Firstly, the scientific meaning of the results must be preserved and never distorted in whatever story carried in the news media. Secondly, ethical principles of health research must never be compromised. In order to achieve these two caveats, I normally recommend that the task can be best accomplished by the combined efforts of the scientists and the news media journalists working closely together. By this approach, an acceptable balance is created between the research scientists and the journalists most of whom, in the Kenyan setting, are lay in health sciences.

But what type of scientific articles are worth highlighting to the public through the lay media? In a developing, country like Kenya, the priority areas should include (but not restricted to) situations calling for personal and public health intervention, such as, infections and infectious diseases, including waterborne diseases, nutritional disorders and emerging noncommunicable diseases,

Many examples come to mind, but I will refer to only three published in this journal dealing with malaria prevention. The article by Oloo et al (3) entitled. The effect of permethrin impregnated sisal curtains on vector density and malaria incidence: a pilot study was based on a comparative study conducted in Ahero which is a rural area near Kisumu. The researchers concluded that "covering of eaves and windows with permethrin impregnated sisal curtains reduced mosquito vector density and the number of mosquito bites to individuals sleeping in protected houses" as compared to those who did not use the curtains. Later, researchers from the same institution led by Karanja et al(4) 
conducted a survey to determine "knowledge and attitudes to malaria control and the acceptability of permethrin impregnated sisal curtains" in another rural community $15 \mathrm{~km}$ northwest of Kisumu and established that there was need for affordable means of mosquito control, such as sisal strand curtains for such rural communities which are acutely aware of problems associated with malaria control but are constrained from taking any action because of lack of resources.

Another group of researchers from the lnternational Centre of Insect Physiology and Ecology (ICIPE) conducted another comparative research using permethrin impregnated wall cloth, nick named " Mbu cloth" - Mbu is the Kiswahili language word for mosquito). The study was carried out in the Marigat area of Baringo district, which is mesoendemic for malaria. Findings of this study by Mutinga et al (5) revealed that the use of mbu cloth resulted in $73 \%$ reduction of malaria parasite prevalence in school children.

Clearly these three studies show effectiveness of an affordable preventive intervention measure which should be popularized in those Kenyan rural communities with high malaria transmission. This is where the need to inform and educate people through the lay media is foremost. As far as I am aware, there has been no animated effort to disseminate these worthy findings - the result? They remain within the covers of our journal as many Kenyans (the tax payers and funders of research) continue to bear the brunt of morbidity and mortality of this common disease.

There is considerable concern by the majority of the scientific community in Kenya that the coverage of scientific research by the news media is sometimes exaggerated, inaccurate, over-generalized, and misleading. Unlike in developed communities, there are not sufficient numbers and desired calibre of science reporters and writers in Kenya. For instance, before joining the New England Journal of Medicine in 1993 as a deputy editor, Robert Steinbrook, who is a medical doctor, worked for about seven years as a medical writer for a lay newspaper- the Los Angeles Times.

This local scenario, in my view, calls for the input of those who own, publish and edit scientific journals in this country in order to pass health information to the lay public in a manner that is ethical, and without distortion of the scientific messages. Clarity and simplicity are key considerations in communicating such information. However, I cherish the caution that Robert Steinbrook(2) sounded, which is applicable equally in Kenya, namely that medical journals should not attempt to take the place of news media or the news media to try to take the place of medical journals. For the two groups to operate together for the benefit of the public, there should be mutual and symbiotic relationship.

Although not the focus of this editorial, I must add that the policy makers should be addressed as well and critical evidence emanating from scientific research communicated to them for consideration in formulation of health policies.

How else would we educate, motivate and mobilize the Kenyan populace to take care of their own health, as well as nurture the notion and philosophy of evidence-based healthcare and translate it into a reality?

W. Lore, MD, FRCP, FACA

Editor-in-Chief

East African Medical Journal

\section{REFERENCES}

1. Moynihan, R., Bero, L., Ross-Degman, D., Henry, D., Lee, K., Watkins, J. et al . Coverage of the news media of the benefits and risks of medications. N. Engl. J. Med. 2000; 342: $1645-1650$.

2. Steinbrook, R.: Medical journals and medical reporting. N. Engl. J. Med. 2000; 342:1668-1671.

3. Oloo, A. J., Mudegu, J. V., Ngare, D. K., Ogutu, R. O., Ondijo, S. O., Odada, P. S. et al. The effect of permethrin impregnated sisal curtains on vector density and malaria incidence: a pilot study. East Afr. Med. J. 1993; 70: 475-477.

4. Karanja, D. M. S., Alaii, J., Abok, K., Adungo, N. I., Githeko, A. K., Seroney, I: et al Knowledge and attitudes to malaria control and acceptability of permethrin impregnated sisal curtains. East Afr. Med. J. 1999; 76: 42-46.

5. Mutinga, M. J., Mnzava, A., Kimokoti, R., Nyamori, M., and Ngindu A. M. Malaria prevalence and morbidity in relation to the use of permethrin-treated wall cloths in Kenya. East Afr. Med. J. 1993; 70:756-762. 